\title{
Article \\ Cyclic oxidation properties of the near nanocrystalline AlCrFe- CoNi high-entropy alloy coatings applied by atmospheric plasma spraying technique
}

\author{
F. Ghadami ${ }^{1,}$, M.A. Davoudabadi ${ }^{3}$ and S. Ghadami ${ }^{3}$ \\ 1 Department of Materials Engineering, Tarbiat Modares University, PO Box:14115-143, Tehran, Iran; \\ f.ghadami@modares.ac.ir \\ 2 Department of Physics, Science and Research Branch, Islamic Azad University, Tehran, Iran; \\ amin353535a@gmail.com \\ 3 Department of Materials Engineering, Tarbiat Modares University, PO Box:14115-143, Tehran, Iran; \\ s.ghadami@modares.ac.ir \\ * Correspondence: f.ghadami@modares.ac.ir; Tel.: +(98)-912-5333626
}

\begin{abstract}
Microcrystalline and near nanocrystalline $\mathrm{AlCrFeCoNi} \mathrm{high-entropy} \mathrm{alloy} \mathrm{(HEA)} \mathrm{coatings}$ were applied on Inconel 718 superalloy using air plasma spraying (APS) process. High-temperature oxidation behavior of the microcrystalline and near nanocrystalline AlCrFeCoNi HEA coated superalloy were examined at $110^{\circ} \mathrm{C}$ under the air atmosphere for 50 cycles under cyclic heating and cooling ( $1 \mathrm{~h}$ for each cycle). The oxidation kinetics of both nanocrystalline and microcrystalline coated superalloy was accordingly analyzed by weight change measurement. It was noticed that the uncoated and coated followed the parabolic rate law of the oxidation. X-ray diffraction (XRD), field emission scanning electron microscopy (FESEM), energy dispersive X-ray analysis (EDS), and elemental mapping techniques were used to analyze the oxidized coated and uncoated samples. In the HEA coated superalloy, $\mathrm{Fe}, \mathrm{Ni}, \mathrm{Co}$, and $\mathrm{Al}$ were oxidized in the inter-splat region, whereas the splats which consist mainly of $\mathrm{Ni}$ and $\mathrm{Cr}$ remained unoxidized. Because of the formation of compact and adhesive thin $\mathrm{NiO}, \mathrm{CoO}$ oxides, and spinels together with the $\mathrm{Al}_{2} \mathrm{O}_{3}$ oxide scale on the surface of the coating during oxidation, the developed nanocrystalline HEA coating shows better oxidation resistance than the microcrystalline HEA coating.
\end{abstract}

Keywords: AlCrFeCoNi high-entropy alloy coating, APS deposition; Cyclic oxidation

\section{Introduction}

High-entropy alloys (HEAs) are a new group of alloys that demonstrate exceptional properties. These alloys are representing the potential for the design and production of advanced industrial and structural parts in the various forms of as-cast, sintered, and coating for demanding environments [1]. The preparation, characterization, and application of high-entropy alloys and coatings (HEA) have been the focus of the research efforts since the mid-2010s [2-4].

On account of the multiple principal metallic compositions with an equal or nearequal atomic percentage, HEAs have outstanding mechanical and chemical properties such as higher hardness, superior mechanical strength, and excellent wear resistance. These types of materials have been recently interested to use as catalysts, magnetic, superconducting, and thermoelectric materials. Some groups of HEAs containing $\mathrm{Al}$ and $\mathrm{Ni}$ are mainly exhibited superior chemical and mechanical properties such as greater values in thermal stability, hardness, and wear resistance. Subsequently, $\mathrm{Ni}$ or $\mathrm{Co}$ is one of the base alloying forming a single-phase BCC or chemically ordered BCC (B2) structure in the equimolar $\mathrm{AlCrFeCoNi}$ composition. In the case of the $\mathrm{HEAs}, \mathrm{Al}$ as the alloying element can considerably influence the phase formation of the $\mathrm{AlCrFeCoNi}$ alloys. Chemical and mechanical properties of the bulk $\mathrm{AlCrFeCoNi}$ alloys have been previously investigated 
in detail [2,3,5-7]. Most of these studies were announced that the AlCrFeCoNi alloy system can be used in industrial parts against chemical and mechanical attacks.

In another vantage point, HEA coating can be successfully used due to the limitations of the production of bulk or as-cast HEA parts. It is previously divulged that the thermal spraying processes are enabled to deposit different types of HEA materials on the various substrates [8-11]. As one of the most widely-used thermal-spraying methods, air plasma spraying (APS) deposition is a potential processing route for developing HEAs owing to its simple deposition process, a wide range of HEA powder feedstock variety, and excellent deposition efficiency. Thus, the APS process is recently a well-known method for deposition of industrial HEA coatings [2,12]. The isothermal and cyclic oxidation resistance of AlCrFeCoNi HEA alloys and coatings is mainly related to its capability to form a dense, continuous, and slow-growing oxide scale when exposed to the high-temperature environment (especially the temperatures greater than $\left.1000^{\circ} \mathrm{C}\right)[5,6,13]$.

Currently, the APS process is introduced for nanocrystalline coatings using microsized powder particles by mechanical milling. It is one of the advanced methods to produce nanocrystalline powder particles by using the ball milling process. The milled particles get fractured, resulting in the formation of the nano-crystalline structure. In addition, nanocrystalline powder particles possess excellent properties compared to conventional counterparts such as strength, elastic modulus, microhardness, ductility, thermal conductivity, wear resistance, corrosion, and oxidation resistance $[2,12]$. When the nanocrystalline form of the $\mathrm{AlCrFeCoNi} \mathrm{HEA} \mathrm{is} \mathrm{used} \mathrm{as} \mathrm{a} \mathrm{feedstock} \mathrm{powder,} \mathrm{the} \mathrm{thermal} \mathrm{properties}$ of the $\mathrm{AlCrFeCoNi} \mathrm{HEA} \mathrm{coating} \mathrm{were} \mathrm{accordingly} \mathrm{improved.} \mathrm{The} \mathrm{agglomerates} \mathrm{of} \mathrm{the}$ HEA nanopowders formed from the conventional sized HEA powder were used for depositing nanocrystalline HEA coatings. It is learned that only limited works are available on the study of nanocrystalline HEA coatings taken from blends and milled $\mathrm{AlCrFeCoNi}$ HEA powder $[8,14,15]$.

The present work aimed at the analysis of the structural characteristics and hightemperature oxidation properties of APS sprayed microcrystalline and nanocrystalline $\mathrm{AlCrFeCoNi} \mathrm{HEA} \mathrm{coatings} \mathrm{under} \mathrm{the} \mathrm{air} \mathrm{atmosphere} \mathrm{at} 1100^{\circ} \mathrm{C}$ for enhancing the performance and stability of the future generations of gas turbine and jet engine components. For this purpose, the $\mathrm{AlCrFeCoNi} \mathrm{HEA} \mathrm{feedstock} \mathrm{powder} \mathrm{with} \mathrm{a} \mathrm{nanocrystalline} \mathrm{structure}$ was synthesized using the high-energy ball-milling method. Besides, conventional microcrystalline and nanocrystalline AlCrFeCoNi HEA coatings were deposited via the APS deposition process. Microstructural characteristics, phase composition as well as cyclic oxidation behavior of the micro- and nanocrystalline coatings at $1100{ }^{\circ} \mathrm{C}$ have been evaluated. Finally, the comparative structure and composition of the oxide scale formed on both micro- and nanocrystalline coatings have also been analyzed by means of FESEM, XPS, XRD, and EDS tests.

\section{Materials and Methods}

\subsection{Base material and coating powder}

The raw elemental $\mathrm{Al}, \mathrm{Cr}, \mathrm{Fe}, \mathrm{Co}$, and Ni powders (with the purity of $99.5 \%$ ) with the equimolar composition ( $20 \mathrm{wt} . \%$ ) were milled using a high-energy ball milling process to obtain microcrystalline and nanocrystalline $\mathrm{AlCrFeCoNi} \mathrm{HEA} \mathrm{powder.} \mathrm{In} \mathrm{this} \mathrm{case,} \mathrm{the}$ powder mixture was dry-ball milled in a conventional rotating ball mill under Ar gas control with hard chrome plated stainless steel balls as a milling/grinding medium for 5 $\mathrm{h}$ and $25 \mathrm{~h}$ under $300 \mathrm{rpm}$ to achieve homogenous microcrystalline and nanocrystalline powders respectively. All milled powders were then sieved individually ( -75 to $+15 \mathrm{pm})$ in order to obtain the optimal particle size distribution of the powders suitable for the APS thermal spraying process. In addition, the Inconel 718 superalloy was chosen as a base material for deposition of the micro- and nanocrystalline HEA coatings which is the most preferred choice for the hot section of gas turbine engine component and other structural applications which works in high temperature, aggressive environment, and its excellent mechanical properties and high-temperature phase stability. The chemical composition of 
Inconel 718 contains: $\mathrm{Ni}-52.37 \%, \mathrm{Cr}-19 \%, \mathrm{Fe}-18.5 \%$, $\mathrm{Ta}-5.13 \%$, $\mathrm{Mo}-3.05 \%, \mathrm{Al}-0.5 \%$, $\mathrm{Ti}-0.9 \%, \mathrm{Si}-0.18 \%, \mathrm{Mn}-0.18 \%$ and traces of $\mathrm{Cu}$ and $\mathrm{C}$.

\subsection{Development of microcrystalline and nanocrystalline HEA coatings}

A commercial APS spraying system was utilized for the deposition of microcrystalline and nanocrystalline AlCrFeCoNi HEA coatings. In this case, the average thickness of the developed coatings was chosen between 300 and $350 \mu \mathrm{m}$. Given that, The APS process was conducted using an $\mathrm{Ar} / \mathrm{H}_{2}$ plasma gas mixture. Table 1 summarizes the main APS parameters used for both types of microcrystalline and nanocrystalline AlCrFeCoNi HEA coatings. At this rate, the optimized APS parameters were selected from our previous works $[11,16,17]$. Before the APS coating process, the superalloy substrates' surface was first roughened using manual sandblasting equipment to achieve an average surface roughness (Ra) of $5 \mu \mathrm{m}$. In due course, the blasted substrates were then cleaned for 10 minutes in an ultrasonic cleaning bath containing water and ethanol. All cleaned surfaces were dried accordingly. The twin air jet was utilized backward of the substrate surface due to the prevention of (any) thermal effects during the APS process.

Table 1. APS process parameters for the deposition of the HEA AlCrFeCoNi coatings.

\begin{tabular}{ll}
\hline Parameter & Value \\
\hline Nozzle diameter $(\mathrm{mm})$ & 6 \\
Plasma gas flow Ar $(1 / \mathrm{min})$ & 65 \\
Secondary gas flow $\mathrm{H}_{2}(1 / \mathrm{min})$ & 3 \\
Carrier gas Ar $(1 / \mathrm{min})$ & 2 \\
Arc current $(\mathrm{A})$ & 700 \\
Arc voltage $(\mathrm{V})$ & 58 \\
Spraying angle $\left({ }^{\circ}\right)$ & 90 \\
Number of passes & 8 \\
Powder feed rate $(\mathrm{g} / \mathrm{min})$ & 36 \\
Standoff distance $(\mathrm{mm})$ & 140 \\
\hline
\end{tabular}

\subsection{Characterization of the HEA Coatings}

The cross-sectioned coated and uncoated substrates were cloth polished by various grit emery sheets. Then the polished substrates were examined by Vickers microhardness tester, $\mathrm{X}$-ray diffraction analysis (XRD), and field emission scanning electron microscope (FESEM) observation equipped with energy dispersive X-ray (EDS) analysis. The porosity in the coating was measured for both microcrystalline and nanocrystalline HEA coatings by inverted transmitted-light metallurgical microscope (motorized version). To ascertain the amount of porosity (in \%), the measurement was taken at various places on the optical micrograph which is taken from coated sample and analyzed using an image analysis software (Image-J NIMH, ver. 1.2, USA). In this case, at least five structural image micrographs with the same magnification (1000×) were performed for the image analyzing process for all microcrystalline and nanocrystalline HEA coatings. The microhardness measurement was carried out on the coated samples by Vickers micro-indentation hardness tester based on ASTM E92. The test conditions are: the applied load 200 gr, apical angle $136^{\circ}$ with an approach velocity of $5-60 \mu \mathrm{m} / \mathrm{sec}$, and 15 seconds dwell time. The XRD profiles for the scale and powders at different milling times was carried out by the X-ray Diffractometer which is operated at an accelerating voltage $35 \mathrm{kV}$ and acceleration current of $20 \mathrm{~mA}$ with a scan rate of 40/min and scanning range of 10 to 80 degree (20) using CuK $\alpha$ source $(\lambda=1.54056 \AA)$. FESEM with EDS is also used to characterize the cross-sectional morphology, surface morphology, and X-ray mapping of the coatings. The porosity and average microhardness value of the microcrystalline and nanocrystalline HEA coating are presented in Table 2. 
Table 2. Percentage of porosity (\%) and microhardness (in HV) of the APS deposited HEA AlCrFeCoNi coatings.

\begin{tabular}{lll}
\hline Structural mode & Porosity & Microhardness \\
\hline Microcrystalline & 1.3 & $542 \pm 19$ \\
Nanocrystalline & 1.6 & $492 \pm 12$ \\
\hline
\end{tabular}

\subsection{High-temperature oxidation study under cyclic conditions}

The study of the cyclic oxidation behavior of the uncoated superalloy, as well as microcrystalline and nanocrystalline $\mathrm{AlCrFeCoNi} \mathrm{HEA}$, coated samples was conducted for $50 \mathrm{~h} /$ cycles at a temperature of $950^{\circ} \mathrm{C}$ in air. Each cycle includes $1 \mathrm{~h}$ of heating followed by 20 min of cooling at room temperature. Initially, the substrate weight was measured by an electronic scale that has an accuracy of $10^{-3} \mathrm{~g}$. In the first cycle, the three samples were put within the ceramic container and placed inside the furnace, and heating time was counted. After $1 \mathrm{~h}$ of heating, the samples along with crucibles were taken out from the furnace and allowed to cool for $20 \mathrm{~min}$. Then the heated samples were weighed separately and the weight gain value was accordingly noted. In the second cycle, the samples in the crucibles were again placed inside the muffle furnace, and the above processes of 1 $\mathrm{h}$ heating, $20 \mathrm{~min}$ of cooling, and weight measurement were repeated. The same procedure was repeated for all 50 cycles. After each cycle of study, the samples were weighed and specific weight changes of the coated specimens, that is difference in weight with respect to the initial weight was measured and noted for all $50 \mathrm{~h} / \mathrm{cycle}$. At the end of each cycle, the specimens were visualized concerning color, luster, or all the other physical aspects of the oxide scales being formed. XRD, FESEM as well as X-ray elemental mapping techniques were used to describe the characteristics of the scale formed on the oxidized microcrystalline and nanocrystalline HEA coatings.

\section{Results and Discussion}

\subsection{Characterization of the nanocrystalline HEA powder}

Figure 1 indicates the morphological structure of the micro- and nanocrystalline AlCrFeCoNi HEA powders obtained using FESEM observations which were prepared after 5 and $25 \mathrm{~h}$ of the ball-milling process. According to Figure 1a, the initial milling process leads to the development of a relatively homogenous microcrystalline AlCrFeCoNi HEA powder consisting of numerous agglomerates. In this case, the average size of the fine particles was measured about $42 \mu \mathrm{m}$ using ImageJ analysis. By elongating the ball milling duration to obtained powders with a finer structure, the average size of ultrafine particles in an agglomerate was substantially reduced to $185 \mathrm{~nm}$ (Figure 1b). For a deeper understanding, Figure 2 shows the bright-field (BF) TEM images of the nanocrystalline AlCrFeCoNi HEA powder synthesized after $25 \mathrm{~h}$ of the ball-milling process. As can be observed from the nanocrystalline powder (Figure 2a), each powder particle has a fine crystalline morphology and also contained numerous deformed and agglomerated metallic AlCrFeCoNi alloy particles. In conformity with the corresponding selective area diffraction (SAD) pattern shown in Figure $2 b$, the detected diffraction rings were indexed as major crystallographic planes which represented a nanostructured solid solution phase. In another point of view, the presence of nanoparticles in the $25 \mathrm{~h}$ milled powder is confirmed by the bright spots coinciding with the rings, and the nano-scaled structure was proved by the sharp rings in the corresponded SAD pattern $[7,14,18,19]$. 

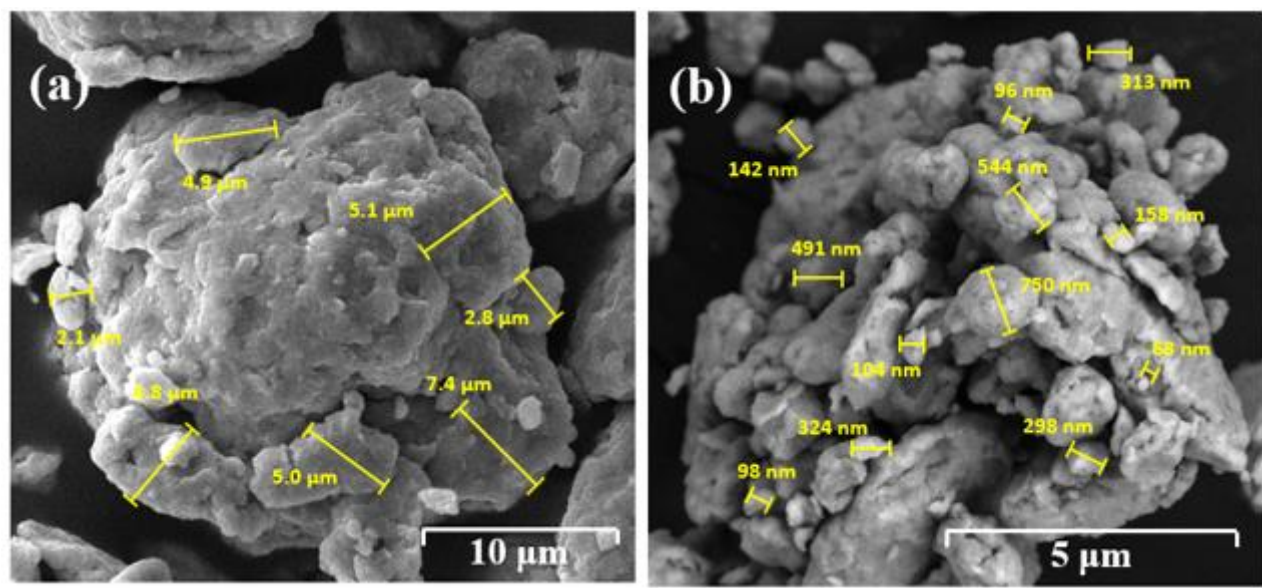

Figure 1. (a) FESEM morphology of a) microcrystalline AlCrFeCoNi HEA powder and (b) nanocrystalline AlCrFeCoNi HEA powder.
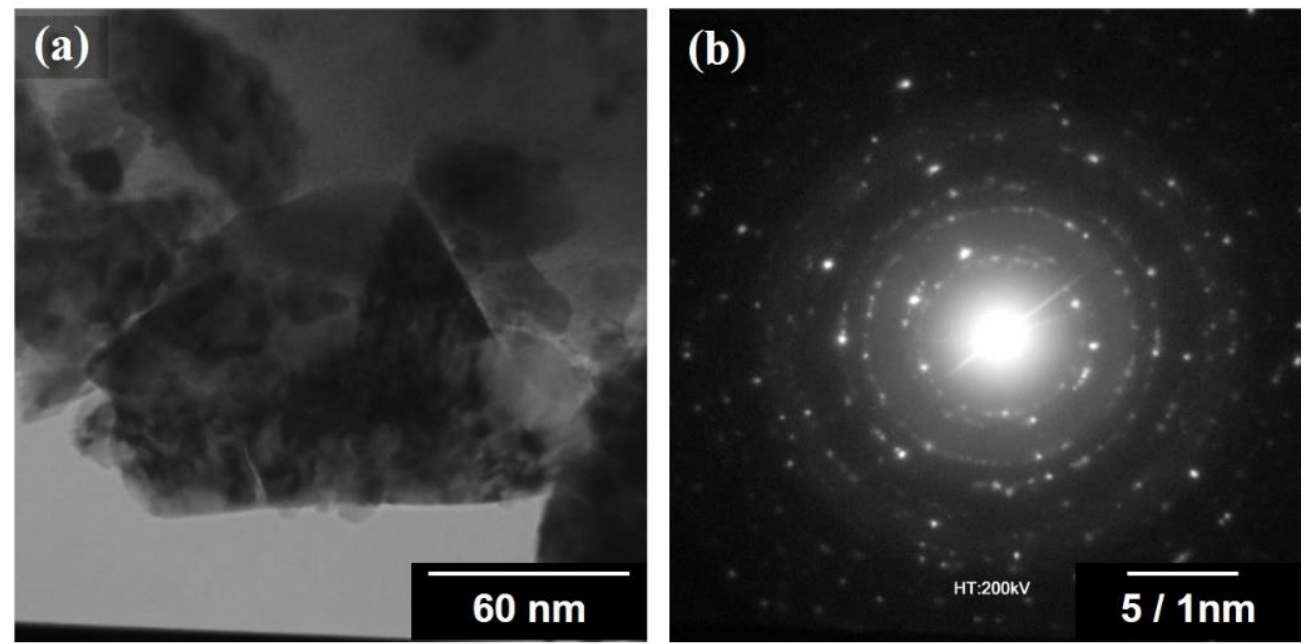

Figure 2. TEM morphology of the nanocrystalline AlCrFeCoNi HEA powder (a) and selected area electron diffraction pattern of diffraction spots $(b)$.

Figure 3, shows the obtained AAS data (wt.\%) for the conventional and nanocrystalline HEA AlCrFeCoNi powders. As can be seen, the amount of oxygen in the milled nanocrystalline HEA powders was substantially increased compared to the conventional HEA powder, due to the partial oxidation of the powder mixture during the high-energy ball milling process. A similar alloying composition has been also used in our previous investigation [20]. 


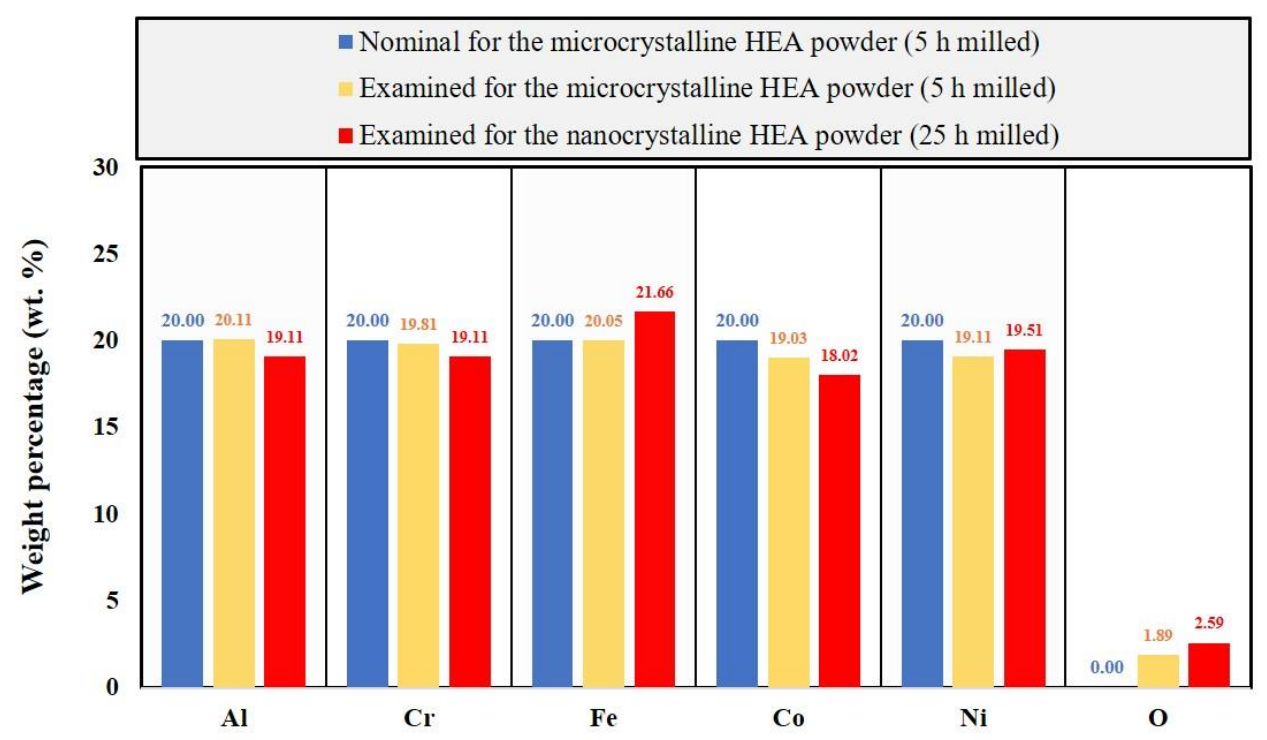

Figure 3. Atomic absorption spectroscopy (AAS) results (wt.\%) for the microcrystalline and AlCrFeCoNi HEA powders after ball-milling process achieved from 5 and $25 \mathrm{~h}$ of milling process respectively (All AAS weight percentage results were presented with an accuracy of $10^{-2}$ ).

\subsection{Characterization of the nanocrystalline HEA coating}

The cross-sectional FESEM micrograph of the microcrystalline and nanocrystalline $\mathrm{AlCrFeCoNi} \mathrm{HEA} \mathrm{coating} \mathrm{on} \mathrm{IN718} \mathrm{superalloy} \mathrm{substrate} \mathrm{is} \mathrm{shown} \mathrm{in} \mathrm{Figures} \mathrm{4a} \mathrm{and} \mathrm{b}$ respectively. As can be seen, Figure 4a shows the structure of the solid coating with a lamellar morphology with the presence of the structural pores, microporosities, and oxide stringers formed as dark contrast spots near the boundary of the substrate and the coating layer. The average thickness of the as-sprayed microcrystalline AlCrFeCoNi HEA coating was found about $200 \mu \mathrm{m}$ which was measured from its FESEM micrograph (Figure 4a) and for the nanocrystalline $\mathrm{AlCrFeCoNi} \mathrm{HEA} \mathrm{coating,} \mathrm{the} \mathrm{average} \mathrm{coating} \mathrm{thickness} \mathrm{was}$ measured about $\sim 250 \mu \mathrm{m}$. So, it is clear that the coating (Figure $4 \mathrm{~b}$ ) formed from the nanocrystalline AlCrFeCoNi HEA powder has higher amounts of microporosities and oxide stringers compared with the microcrystalline one. Additionally, compared to the measured microhardness of microcrystalline AlCrFeCoNi HEA coating $(492 \pm 12 \mathrm{HV})$, according to table 2, the average microhardness of the nanocrystalline coating was found to be higher $(542 \pm 19 \mathrm{HV})$. The interesting point is that in spite of higher amounts of structural pores in the as-sprayed nanocrystalline $\mathrm{AlCrFeCoNi} \mathrm{HEA} \mathrm{coating} \mathrm{(with} 1.6 \%$ porosity), its microhardness was comparably higher than that of the as-sprayed microcrystalline AlCrFeCoNi HEA coating (with 1.3\% porosity), as the same reported by Jiang et al. [15] and Ghadami et al. $[18,21,22]$ for similar cases of nanostructured Ni-based coatings applied by other methods of the thermal spraying process. For this study, the as-sprayed nanocrystalline $\mathrm{AlCrFeCoNi}$ HEA coating obtained from $25 \mathrm{~h}$ milled powder feedstock exhibits about $~ 10 \%$ increase in microhardness value as compared with the corresponding microcrystalline HEA coating obtained from $5 \mathrm{~h}$ milled powder. 

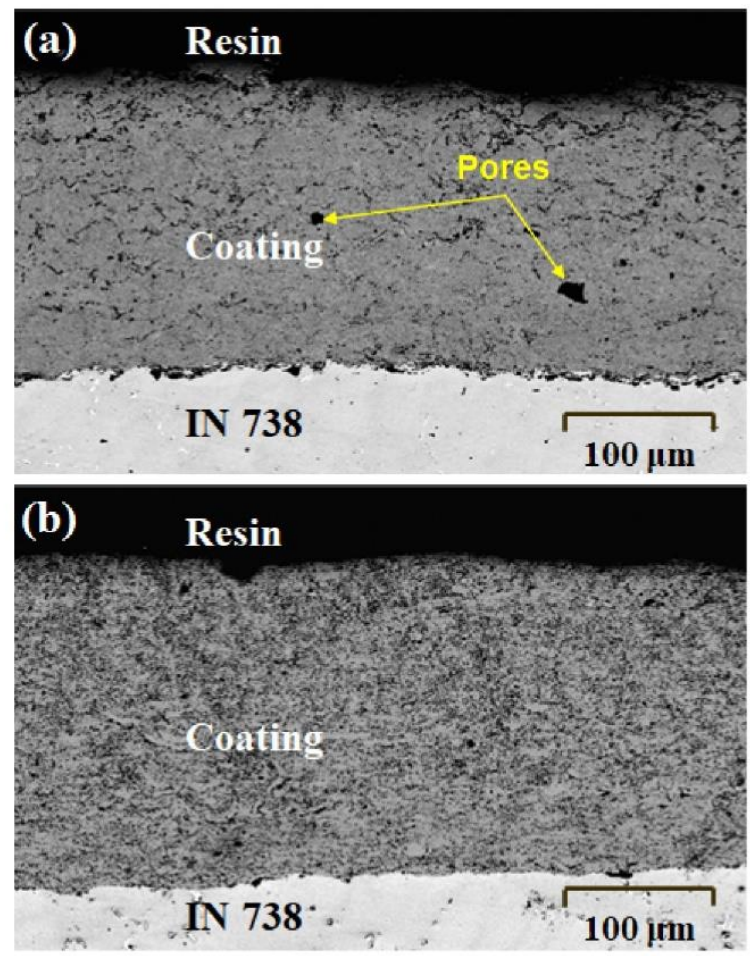

Figure 4. (a) Microcrystalline AlCrFeCoNi HEA coating (b) nanocrystalline AlCrFeCoNi HEA coating.

The XRD profile of the microcrystalline and nanocrystalline AlCrFeCoNi HEA powders and their developed coatings were illustrated in Figure 5. As can be observed, the diffraction pattern of the as-sprayed micro- and nanocrystalline AlCrFeCoNi HEA powder coatings exhibits similar intensity with those the micro- and nanocrystalline $\mathrm{AlCrFeCoNi}$ HEA feedstock powder obtained from 5 and $25 \mathrm{~h}$ of the milling process, indicating that no major phase transformation has happened during the high energy ballmilling and APS spraying process. Therewithal, the major BCC (B2) structure is detected for both cases of micro- and nanocrystalline $\mathrm{AlCrFeCoNi} \mathrm{HEA} \mathrm{powders.} \mathrm{This} \mathrm{finding} \mathrm{is}$ in accordance with another study carried out by Lobel et al. for the as-cast, arc-melted, and spark plasma sintered AlCrFeCoNi HEAs $[17,18]$. In addition, for both cases of assprayed micro- and nanocrystalline AlCrFeCoNi HEA coatings a major BCC (B2) phase as well as a minor FCC (A1) phase were also appeared in the coating after the XRD test. Besides, from the diffraction pattern of the as-sprayed nanocrystalline coating, it is also clear that the relative intensity of the detected chemically ordered FCC (A1) phase is comparably lower than the as-sprayed microcrystalline coating, resulting in the stabilization of the BCC (B2) phase after $25 \mathrm{~h}$ of high energy ball milling process due to the increment of plastic deformation of powder particles caused by ball-particle collisions. Indeed, for the nanocrystalline $\mathrm{AlCrFeCoNi} \mathrm{HEA} \mathrm{coating,} \mathrm{Al}$ tends to stabilize the $\mathrm{BCC}$ phase in the coating structure [6]. Individual elements can majorly influence on phase evolution of HEA coatings. In this matter, Ang et al. [3] reported that $\mathrm{Fe}, \mathrm{Cr}$, and $\mathrm{Al}$ tend to favor the formation BCC phase, whereas Ni tends to stabilize the FCC phase. Nevertheless, corresponding to the peak broadening around 46.5 and $59^{\circ}$ of diffraction angles for both nanocrystalline powder ( $25 \mathrm{~h}$ milled) and nanocrystalline as-sprayed coating, the formation and development of the amorphous (or ultrafine-grained) phases in APS sprayed coating structure may be attributed to the rapid solidification of the partially-melted particles during APS spraying process. Similar results were also obtained elsewhere $[19,20]$. In another point of view, due to an intense crash between the ball and the powder mixture during the high-energy ball milling process, the overall amount of dislocations, distortions, and severe plastic deformation can increase. Subsequently, with an increment of the amount of plastic deformation, the lattice parameters and the grain size of the powders and their developed coatings were accordingly decreased [19]. 


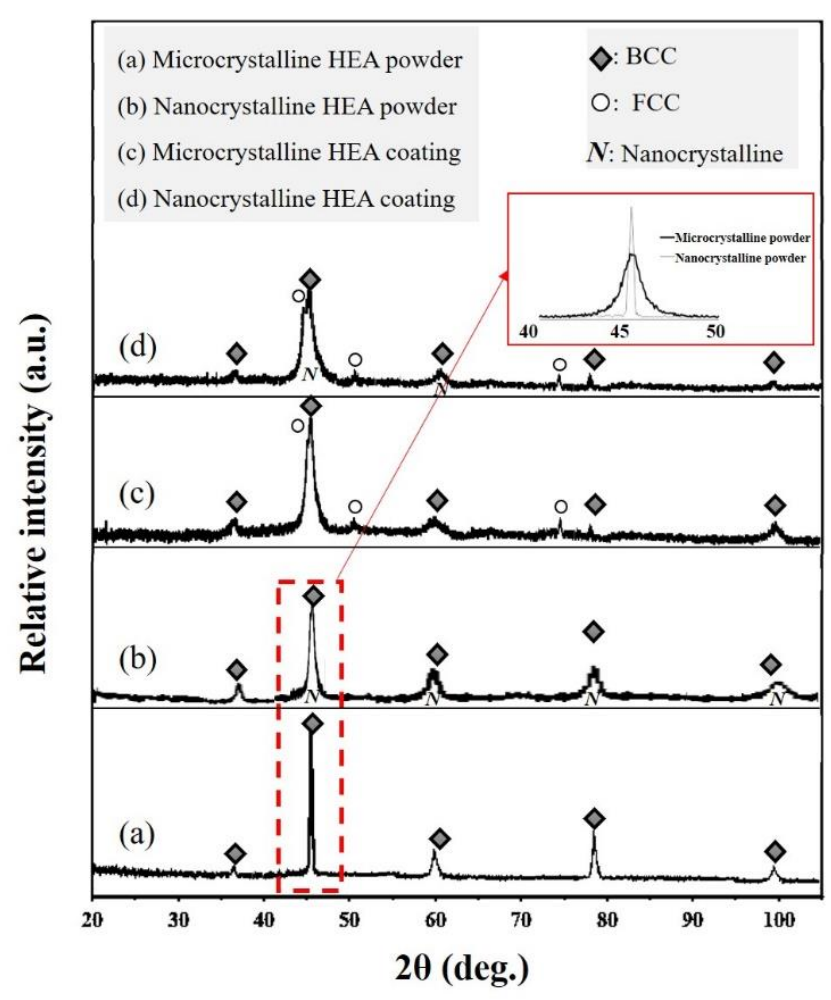

Figure 5. (a) and (b) XRD pattern for micro- and nanocrystalline AlCrFeCoNi HEA powder, (c) and (d) for as-sprayed micro - and nanocrystalline AlCrFeCoNi HEA coatings obtained from milled 5 and $25 \mathrm{~h}$ powder feedstock respectively.

\subsection{Oxidation behavior of the nanocrystalline HEA coating}

Figure 6 depicts the XRD pattern of the oxidation test of microcrystalline and nanocrystalline $\mathrm{AlCrFeCoNi} \mathrm{HEA}$ coating exposed at $1100^{\circ} \mathrm{C}$ after 50 cycles. $\mathrm{NiO}$ (or $\mathrm{CoO}$ ), $\mathrm{Al}_{2} \mathrm{O}_{3}, \mathrm{NiAl}_{2} \mathrm{O}_{4}$ oxides as well as metallic solid solution $\mathrm{BCC}$ phase were detected as the primary phases for the micro- and nanocrystalline coatings. Whereas for nanocrystalline coating, the amount of $\mathrm{Al}_{2} \mathrm{O}_{3}$ is higher than that of microcrystalline coating. Conversely, for the nanocrystalline HEA coating the amounts of other $\mathrm{NiO}, \mathrm{CoO}$ oxides together with $\mathrm{NiAl}_{2} \mathrm{O}_{4}\left(\right.$ or $\left.\mathrm{CoAl}_{2} \mathrm{O}_{4}\right)$ spinels are comparably lower than that microcrystalline coating due to the tendency of the formation of dense and adherent alumina oxide scale on the coating surface after 50 cycle $[6,12]$. 


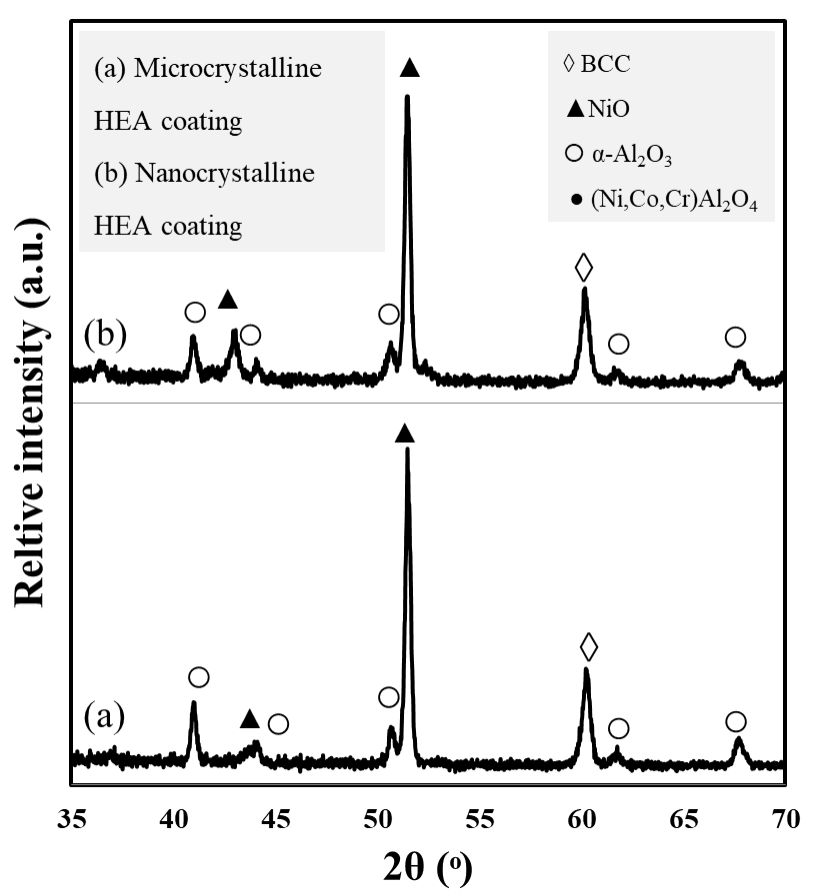

Figure 6. XRD patterns for AlCrFeCoNi HEA coating after 50 cycles of oxidation at $1100{ }^{\circ} \mathrm{C}$ : (a) microcrystalline coating and (b) nanocrystalline coating.

Figure 7 indicates the XPS results of the surface of the oxidized micro- and nanocrystalline $\mathrm{AlCrFeCoNi} \mathrm{HEA} \mathrm{coatings} \mathrm{after} 50$ cycles of the oxidation process at $11000{ }^{\circ} \mathrm{C}$. As can be observed, in the uppermost layer of both types of micro- and nanocrystalline oxidized $\mathrm{AlCrFeCoNi} \mathrm{HEA} \mathrm{coatings,} \mathrm{oxygen} \mathrm{(O1s)} \mathrm{and} \mathrm{a} \mathrm{much} \mathrm{stronger} \mathrm{signal} \mathrm{of} \mathrm{carbon}$ $(\mathrm{C} 1 \mathrm{~s})$ originate from the residue gases, such as $\mathrm{CO}, \mathrm{CO}_{2}$, and $\mathrm{O}_{2}$, in the chamber formed after 50 cycles of the oxidation. Oxygen can also be adsorbed into the coating surface to grow alumina $\left(\mathrm{Al}_{2} \mathrm{O}_{3}\right)$ oxide spots. Apparently, a relatively higher amount of intensity for O1s traces for the nanocrystalline AlCrFeCoNi HEA (Figure $7 \mathrm{~b}$ ) indicated that the value of adherent oxide scales such as alumina formed on the oxidized coating surface was greater than that of the microcrystalline $\mathrm{AlCrFeCoNi} \mathrm{HEA} \mathrm{coating} \mathrm{(Figure} \mathrm{7a).} \mathrm{Indeed,} \mathrm{the}$ high-energy ball milling process to develop nanocrystalline powder feedstock can cause to increase in $\mathrm{C}, \mathrm{N}$, and $\mathrm{O}$ impurities in the powder mixture after $25 \mathrm{~h}$.

Regarding the results of microcrystalline $\mathrm{AlCrFeCoNi} \mathrm{HEA} \mathrm{coating} \mathrm{(Figure} \mathrm{7a),} \mathrm{it} \mathrm{can}$ be concluded that relatively fast-growing oxides (such as major $\mathrm{NiO}, \mathrm{CoO}$, and $\mathrm{Al}_{2} \mathrm{O}_{3}$ oxides as well as minor amounts of $\mathrm{FeO}, \mathrm{Fe}_{2} \mathrm{O}_{3}, \mathrm{Cr}_{2} \mathrm{O}_{3}$ due to their instability at temperatures above $950^{\circ} \mathrm{C}$ ) can easily form after 50 cycles of the oxidation compared with nanocrystalline $\mathrm{AlCrFeCoNi} \mathrm{HEA} \mathrm{coating.} \mathrm{For} \mathrm{instance,} \mathrm{the} \mathrm{high-resolution} \mathrm{spectra} \mathrm{of} \mathrm{Ni2p} \mathrm{for} \mathrm{both}$ cases types of micro- and nanocrystalline coatings mostly belong to the $\mathrm{NiO}$ monoxide component. Additionally, the overall intensity of $\mathrm{Ni}$-ions (which is referred to $\mathrm{Ni}^{2+}$ ) in the oxidized microcrystalline coating is comparably greater than the nanocrystalline one. In contrast, for the microcrystalline AlCrFeCoNi HEA coating, the relative intensity of for high-resolution spectra of Al2p (which referred to alumina oxide component) is almost higher than that of nanocrystalline coating which indicates a greater growth rate of the alumina oxide scale in the microcrystalline coating after 50 cycles of the oxidation at 100 ${ }^{\circ} \mathrm{C}$. As a consequence, after 50 cycles of the high-temperature oxidation process, a uniform and protective alumina layer can form due to its number of oxide spots on the surface (see Al2 $p$ trace for the oxidized nanocrystalline coating in Figure $7 b$ ). Among them, the alumina scale is more adherent and slow-growing due to its higher thermal stability, greater melting, and lower Gibbs free energy compared to other types of oxides. The formation of a uniform and thin alumina layer can promote a lower oxide growth rate and higher cyclic oxidation resistance by controlling the oxygen interdiffusion from the surface into the coating with a nanoscaled structure [18]. 

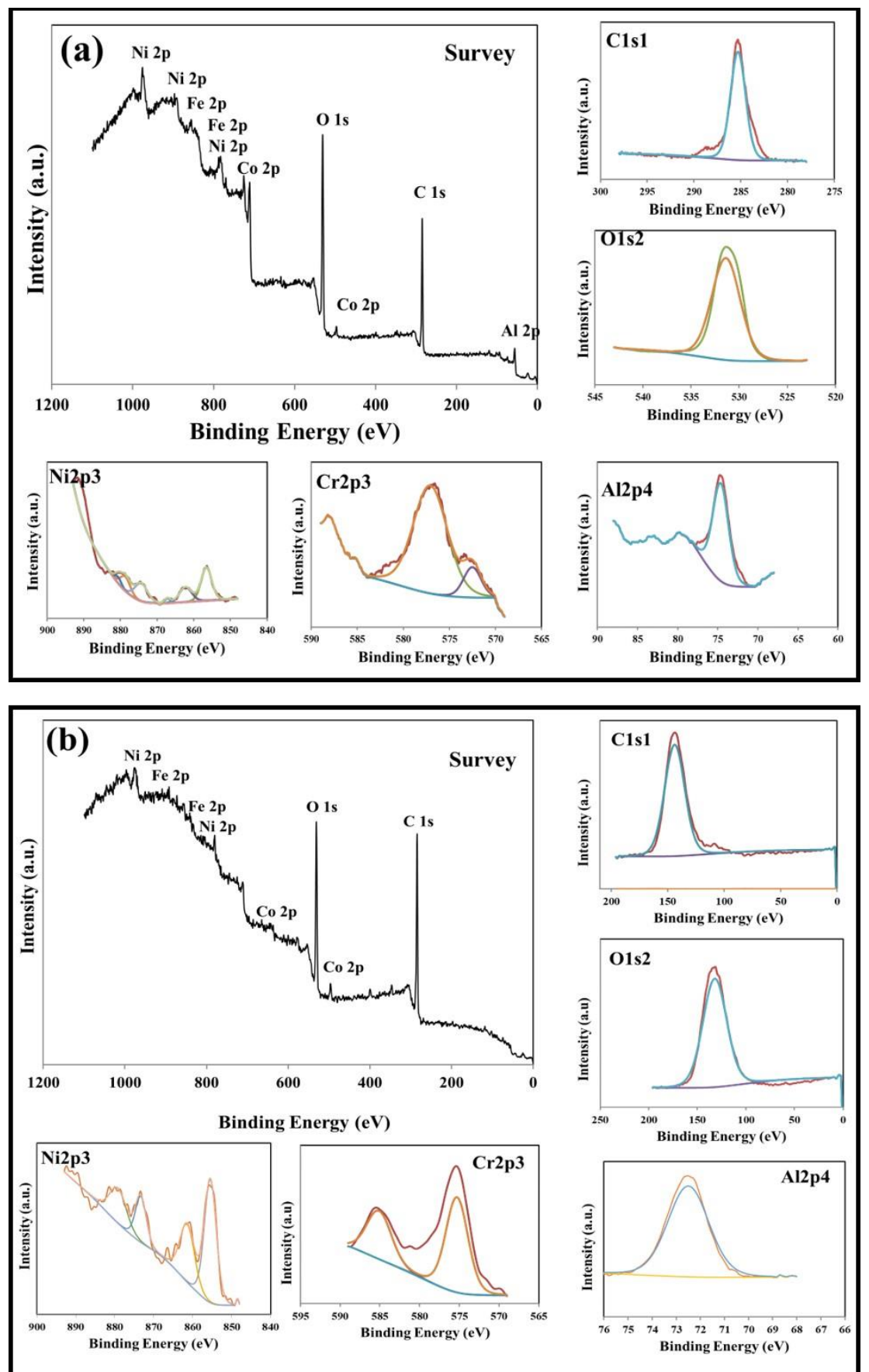

Figure 7. XPS results (survey peaks as well as high-resolution spectra of C1s, O1s, Ni2p, Cr2p, and Al2p peaks) of the surface of the AlCrFeCoNi HEA coating after 50 cycles of the oxidation at 1100 ${ }^{\circ} \mathrm{C}$ : (a) microcrystalline coating and (b) nanocrystalline coating.

Figure 8 displays the mass change per unit area against the number of cycles for the micro- and nanocrystalline AlCrFeCoNi HEA coatings subjected to the high-temperature exposure at $1100{ }^{\circ} \mathrm{C}$ up to 50 cycles. For all cases of the oxidized coatings, the cyclic oxidation process can be divided into two major stages, corresponding to stage 1 with a highrate oxidation behavior and stage 2 with the steady-state (stable) oxidation behavior with continues to the formation of oxide scale cracking process in higher cycles of the oxidation. In the first stages, both micro- and nanocrystalline HEA coatings were directly exposed to the air atmosphere and subjected to oxidation with a relatively high rate, causing the drastic increase in their mass gain (about 2.1 and $1.0 \mathrm{mg} / \mathrm{cm} 2$ for micro- and nanocrystalline coatings respectively). 
During the cyclic oxidation process, for both cases of the HEA coatings, a relatively thin oxide scale can be formed on the $\mathrm{AlCrFeCoNi} \mathrm{HEA} \mathrm{surface} \mathrm{and} \mathrm{plays} \mathrm{as} \mathrm{an} \mathrm{oxide-}$ metal diffusion barrier, resulting in the lower mass gain and prolonging its formation. As can be observed, the higher rate oxidation stage (stage 1) for the microcrystalline HEA coating lasts for 25 cycles, which is almost longer than that of the nanocrystalline HEA coatings (20 cycles). Moreover, the relative weight gain of the nanocrystalline coatings after 50 cycles is relatively reduced by $\sim 58 \%$ when compared with that of the microcrystalline $(1.81 \mathrm{mg} / \mathrm{cm} 2$ for the microcrystalline and $0.75 \mathrm{mg} / \mathrm{cm} 2$ for the nanocrystalline coating). The obtained finding also revealed that the dense and adherent oxide scale (especially the alumina oxide scale with higher thermodynamic stability) is easily formed on the surface nanocrystalline $\mathrm{AlCrFeCoNi}$ HEA coating and demonstrates higher cyclic oxidation resistance compared to the conventional microcrystalline $\mathrm{AlCrFeCoNi} \mathrm{HEA} \mathrm{coat-}$ ing.

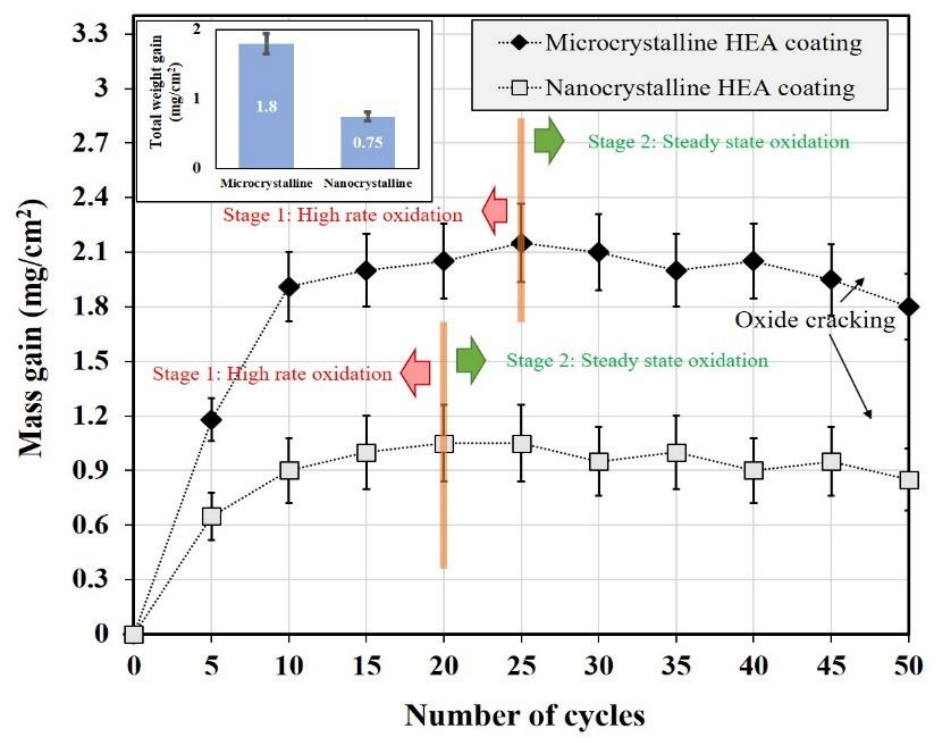

Figure 8. The plot of Weight gain/area vs. the number of cycles for micro- and nanocrystalline $\mathrm{AlCrFeCoNi} \mathrm{HEA} \mathrm{coatings} \mathrm{subjected} \mathrm{to} \mathrm{cyclic} \mathrm{oxidation} \mathrm{at} 1100{ }^{\circ} \mathrm{C}$.

According to the cross-sectional images of the micro- and nanocrystalline coatings after 50 cycles of the oxidation at $1100^{\circ} \mathrm{C}$, (Figure $9 \mathrm{a}$ and $\mathrm{b}$ respectively), the average thickness of the oxide scale in the microcrystalline coating is relatively higher than that nanocrystalline coating $(\sim 4.1 \mu \mathrm{m}$ for microcrystalline coating vs. $\sim 2.6 \mu \mathrm{m}$ for nanocrystalline coating). Moreover, as can be observed from both cases of the oxidized micro- and nanocrystalline coatings, the area percentage of internal oxide spots for oxidized nanostructured NiCoCrAlY coating is higher than the as-received NiCoCrAlY coating. This is due to the finer structure and higher amounts of structural pores and grain boundaries for the nanostructured NiCoCrAlY coating. Also, EDS results of the oxidized coating after $50 \mathrm{cy}-$ cles of oxidation at $1100 \mathrm{C}$ have been listed in Table 3. According to the EDS results from the oxide layer ( $\operatorname{spot} \mathrm{A}$ ), the elemental composition of the oxide layer consisted of the $\mathrm{Ni}$, $\mathrm{Co}, \mathrm{Al}$ metallic oxide, consisting of $\mathrm{NiO} / \mathrm{CoO}$ monoxides and $\mathrm{NiAl}_{2} \mathrm{O}_{4} / \mathrm{CoAl}_{2} \mathrm{O}_{4}$ spinels together with a relatively dense $\mathrm{Al}_{2} \mathrm{O}_{3}$ scale was detected in interior layers for both microand nanocrystalline AlCrFeCoNi HEA coatings.

Gradually, during the cyclic oxidation process at $1100^{\circ} \mathrm{C}$, Fe- and $\mathrm{Cr}$-based oxides and spinels (such as $\mathrm{Cr}_{2} \mathrm{O}_{3}, \mathrm{Fe}_{2} \mathrm{O}_{3}$ oxides together with $\mathrm{NiCr}_{2} \mathrm{O}_{4}, \mathrm{CoCr}_{2} \mathrm{O}_{4}, \mathrm{NiFe}_{2} \mathrm{O}_{4}$, $\mathrm{CoFe}_{2} \mathrm{O}_{4}$ spinels are almost unstable, due to their tendency to decompose and evaporate at temperatures higher than $950^{\circ} \mathrm{C}$. Furthermore, despite the metallic solid solution phase in the coating structure with a bright contrast (spot $\mathrm{B}$ : consisting of $\mathrm{Ni}, \mathrm{Co}, \mathrm{Fe}, \mathrm{Cr}$, and $\mathrm{Al}$ elements), the formation and development of internal oxide regions (spot $\mathrm{C}$ ) were also formed for the oxidized coatings after 50 cycles of the oxidation at $1100{ }^{\circ} \mathrm{C}$. 

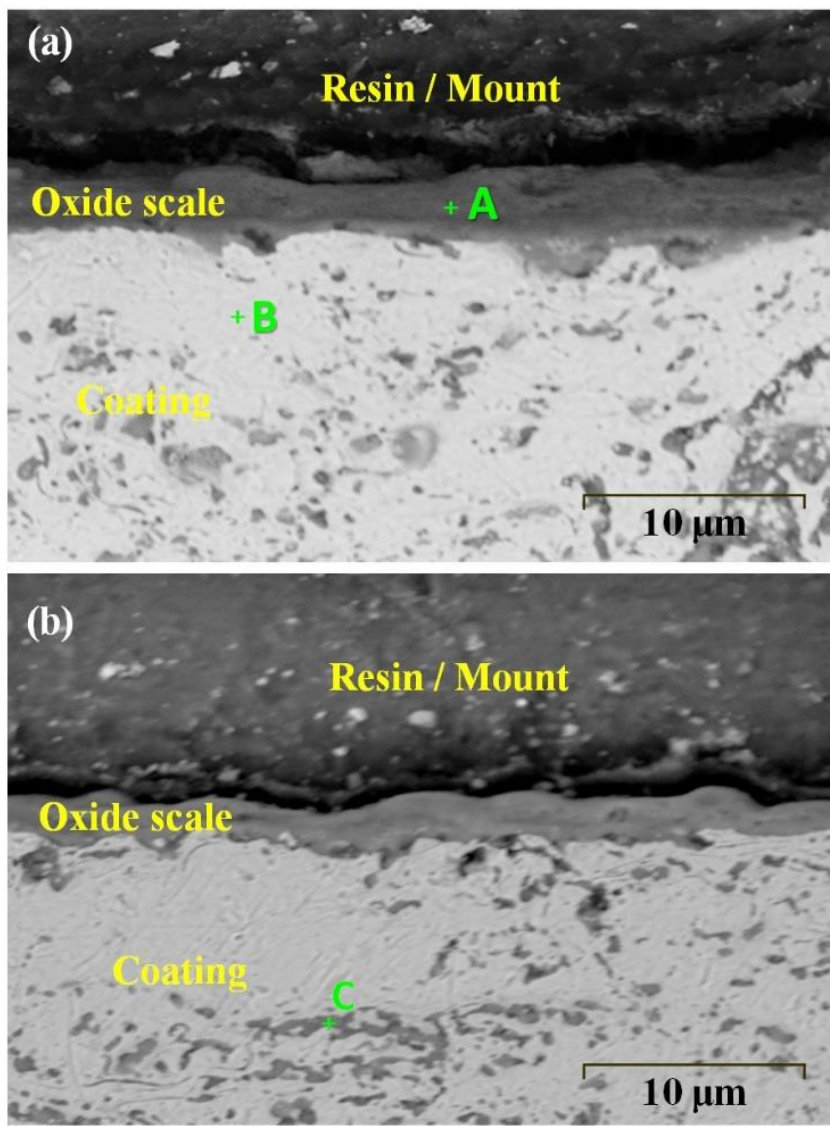

Figure 9. Cross-sectional FESEM micrographs of the oxidized (a) microcrystalline and (b) nanocrystalline $\mathrm{AlCrFeCoNi} \mathrm{HEA}$ coatings after 50 cycles of the cyclic oxidation process at $1100{ }^{\circ} \mathrm{C}$.

Table 3. EDS results of the elemental percentage (wt.\%) of the spots indicated in the oxidized micro- and nanocrystalline coatings (indexed in Figures $9 \mathrm{a}$ and $\mathrm{b}$ ).

\begin{tabular}{|c|c|c|c|c|c|c|}
\hline Indexed region & Al & $\mathrm{Cr}$ & $\mathrm{Fe}$ & Co & $\mathbf{N i}$ & $\mathrm{O}$ \\
\hline A & 16.2 & 12.5 & 13.8 & 11.2 & 9.5 & 36.8 \\
\hline B & 19.9 & 21.5 & 19.3 & $18.3 \quad 19.8$ & 1.2 & \\
\hline C & 16.2 & 16.8 & 18.2 & 15.6 & 17.3 & 15.9 \\
\hline
\end{tabular}

As mentioned elsewhere [23], the high-energy mechanical milling process can synthesize AlCrFeCoNi HEA powder feedstock suitable for APS deposition with an agglomerated morphology composed of numerous fine particles with a nanocrystalline structure. The nanocrystalline HEA powder is susceptible to absorbing a higher volume of oxygen from the atmosphere during the in-flight situation in the APS process compared to the conventional HEA powder with a microcrystalline structure. In fact, the higher amounts of atomic oxygen were maintained in the metallic solid solution BCC phase for the nanocrystalline AlCrFeCoNi HEA coating [24,25]. Therefore, a higher volume fraction of the internal oxides were detected for the oxidized nanocrystalline coating after 50 cycles owing to the reaction of soluble $\mathrm{O}$ and metallic $\mathrm{Al}, \mathrm{Cr}, \mathrm{Fe}, \mathrm{Co}$, and $\mathrm{Ni}$ into the coating cyclic exposure at $1100^{\circ} \mathrm{C}[26,27]$. Among them, the volume fraction of the structural porosity is one of the important factors in the formation and development of the internal oxidation and oxide scale growth for the $\mathrm{AlCrFeCoNi} \mathrm{HEA} \mathrm{coatings} \mathrm{[28-30].} \mathrm{For} \mathrm{the} \mathrm{case} \mathrm{of} \mathrm{the}$ nanocrystalline coating, under cyclic oxidation, the structural porosity $(1.6 \%)$ can promote the oxygen interdiffusion into the coating structure to form internal oxidation at the first stage of cyclic oxidation. Conversely, the higher volume fraction of grain boundaries in nanocrystalline coating together with the formation of internal oxide spots may prevent metallic diffusion and metallic ion consumption to the layers adjacent to the surface [23]. Therefore, the cyclic oxidation resistance of the nanocrystalline AlCrFeCoNi HEA coating 
increases by the formation of adherent and slow-growing oxide scale after 50 cycles at $1100{ }^{\circ} \mathrm{C}$.

\section{Summary and Conclusions}

In this study, the micro- and nanocrystalline $\mathrm{AlCrFeCoNi} \mathrm{HEA} \mathrm{powders} \mathrm{and} \mathrm{coat-}$ ings were developed by means of high-energy mechanical milling and APS deposition processes. The structural characteristics and high-temperature cyclic oxidation behavior of the micro- and nanocrystalline $\mathrm{AlCrFeCoNi} \mathrm{HEA} \mathrm{coatings} \mathrm{were} \mathrm{then} \mathrm{investigated.} \mathrm{Both}$ types of the as-sprayed micro- and nanocrystalline coatings showed a typical lamellar structure consisting of structural porosity and oxide stringers. Also, for both coating cases, a major BCC (B2) phase, as well as a minor FCC (A1) phase, were detected in the coating structure. With respect to the obtained findings, it appears that the nanocrystalline AlCrFeCoNi HEA coating has an outstanding protective coating against cyclic oxidation test at $1100{ }^{\circ} \mathrm{C}$ after 50 cycles compared with the as-sprayed microcrystalline coating. The main causes of this improvement could be related to the formation of thin, protective, and slow-growing oxide scale on the nanocrystalline coating.

The lifecycle of the next generations of high-temperature turbine and aero-engine components mainly depends on the quality and development of a protective oxide scale formed on HEA coatings in the air at an elevated temperature. In this case, the $\mathrm{Al}_{2} \mathrm{O}_{3}, \mathrm{NiO}$, and $\mathrm{CoO}$ oxides as well as their spinels phase is thermodynamically stable at high temperatures under isothermal or cyclic conditions. Among them, the alumina scale is more adherent and slow-growing due to its higher thermal stability, greater melting, and lower Gibbs free energy compared to other types of oxides. The formation of a solid scale for nanocrystalline $\mathrm{AlCrFeCoNi} \mathrm{HEA} \mathrm{acts} \mathrm{as} \mathrm{a} \mathrm{diffusion} \mathrm{barrier} \mathrm{that} \mathrm{increases} \mathrm{the} \mathrm{high-tem-}$ perature oxidation resistance. The rate of reaction is faster at an early stage because the oxygen and the metallic elements are very close to each other. But after a while, the scale becomes thicker, continuous, and more stable, so the diffusion of these elements becomes difficult and thus the mass gain of the specimen decreases in high thermal cycles. The development of oxide scale generally shows a parabolic dependence with time and its durability depends on the concentration of the scale-forming element in the coating material, temperature, oxidizing conditions and alloy microstructure. Therefore, the AlCrFeCoNi HEA nanocrystalline coating may apply against high-temperature corrosion and oxidation attacks at harsh environments for the hot section in the next generation of gas turbine and aero-engines in the future.

Author Contributions: F.G.: conceptualization, methodology, investigation, writing-original draft. S.G.: methodology, writing - review and editing. M.A.D.: investigation, writing-review and editing. All authors reviewed the manuscript.

Funding: Not applicable.

Institutional Review Board Statement: Not applicable.

Informed Consent Statement: Not applicable.

Data Availability Statement: Not applicable.

Conflicts of Interest: None declared.

\section{References}

1. 1 Liu, Y.-x. et al. Oxidation behavior of high-entropy alloys AlxCoCrFeNi $(x=0.15,0.4)$ in supercritical water and comparison with HR3C steel. Transactions of Nonferrous Metals Society of China 25, 1341-1351, doi:https://doi.org/10.1016/S10036326(15)63733-5 (2015).

2. 2 Meghwal, A. et al. Thermal Spray High-Entropy Alloy Coatings: A Review. Journal of Thermal Spray Technology 29, 857-893, doi:10.1007/s11666-020-01047-0 (2020). 
3. 3 Vaidya, M., Muralikrishna, G. M. \& Murty, B. S. High-entropy alloys by mechanical alloying: A review. Journal of Materials Research 34, 664-686, doi:10.1557/jmr.2019.37 (2019).

4. 4 Torralba, J. M., Alvaredo, P. \& García-Junceda, A. High-entropy alloys fabricated via powder metallurgy. A critical review. Powder Metallurgy 62, 84-114, doi:10.1080/00325899.2019.1584454 (2019).

5. $5 \mathrm{Wu}, \mathrm{M}$., Chen, K., Xu, Z. \& Li, D. Y. Effect of Ti addition on the sliding wear behavior of AlCrFeCoNi high-entropy alloy. Wear 462-463, 203493, doi:https://doi.org/10.1016/j.wear.2020.203493 (2020).

6. 6 Erdogan, A., Doleker, K. M. \& Zeytin, S. Effect of Al and Ti on High-Temperature Oxidation Behavior of CoCrFeNiBased High-Entropy Alloys. JOM 71, 3499-3510, doi:10.1007/s11837-019-03679-2 (2019).

7. 7 Yeh, J. W. et al. Nanostructured High-Entropy Alloys with Multiple Principal Elements: Novel Alloy Design Concepts and Outcomes. Advanced Engineering Materials 6, 299-303, doi:https://doi.org/10.1002/adem.200300567 (2004).

8. 8 Ang, A. S. M. et al. Plasma-Sprayed High Entropy Alloys: Microstructure and Properties of AlCoCrFeNi and MnCoCrFeNi. Metallurgical and Materials Transactions A 46, 791-800, doi:10.1007/s11661-014-2644-z (2015).

9. 9 Ghadami, F. \& Aghdam, A. S. R. Improvement of high velocity oxy-fuel spray coatings by thermal post-treatments: a critical review. Thin Solid Films 678, 42-52 (2019).

10. 10 Ghadami, F., Aghdam, A. S. R. \& Ghadami, S. Abrasive wear behavior of nano-ceria modified NiCoCrAlY coatings deposited by the high-velocity oxy-fuel process. Materials Research Express 6, $1250 \mathrm{~d} 1256$ (2020).

11. 11 Sohi, M. H. \& Ghadami, F. Comparative tribological study of air plasma sprayed WC-12\% Co coating versus conventional hard chromium electrodeposit. Tribology International 43, 882-886 (2010).

12. $12 \mathrm{Mu}, \mathrm{Y}$. K. et al. Nano oxides reinforced high-entropy alloy coatings synthesized by atmospheric plasma spraying. Materials Research Letters 7, 312-319, doi:10.1080/21663831.2019.1604443 (2019).

13. 13 Toma, D., Brandl, W. \& Köster, U. The Characteristics of Alumina Scales Formed on HVOF-Sprayed MCrAlY Coatings. Oxid. Met. 53, 125-137, doi:10.1023/A:1004586814837 (2000).

14. 14 Ghadami, F., Sabour Rouh Aghdam, A., Ghadami, S. \& Zeng, Q. Effect of vacuum heat treatment on the oxidation kinetics of freestanding nanostructured NiCoCrAlY coatings deposited by high-velocity oxy-fuel spraying. Journal of Vacuum Science \& Technology A: Vacuum, Surfaces, and Films 38, 022601 (2020).

15. 15 Jiang, H., Lau, M., Tellkamp, V. L. \& Lavernia, E. J. in Handbook of Nanostructured Materials and Nanotechnology (ed Hari Singh Nalwa) 159-213 (Academic Press, 2000).

16. 16 Ghadami, F., Sohi, M. H. \& Ghadami, S. Effect of bond coat and post-heat treatment on the adhesion of air plasma sprayed WC-Co coatings. Surface and Coatings Technology 261, 289-294 (2015).

17. 17 Ghadami, F., Sohi, M. H. \& Ghadami, S. Effect of TIG surface melting on structure and wear properties of air plasmasprayed WC-Co coatings. Surface and Coatings Technology 261, 108-113 (2015).

18. 18 Zakeri, A., Ghadami, F., Rouhaghdam, A. S. \& Saeedi, B. Study on production of modified MCrAlY powder with nano oxide dispersoids as HVOF thermal spray feedstock using mechanical milling. Materials Research Express 7, 015030 (2020).

19. 19 Ghadami, F., Aghdam, A. S. R. \& Ghadami, S. Mechanism of the oxide scale formation in thermally-sprayed NiCoCrAlY coatings modified by CeO2 nanoparticles. Materials Today Communications 24, 101357 (2020).

20. 20 Ghadami, F., Sabour Rouh Aghdam, A. \& Ghadami, S. A comprehensive study on the microstructure evolution and oxidation resistance of conventional and nanocrystalline MCrAlY coatings. Scientific Reports 11, 875, doi:10.1038/s41598020-79323-w (2021).

21. 21 Ghadami, F., Aghdam, A. S. R., Zakeri, A., Saeedi, B. \& Tahvili, P. Synergistic effect of CeO2 and Al2O3 nanoparticle dispersion on the oxidation behavior of MCrAlY coatings deposited by HVOF. Ceramics International 46, 4556-4567 (2020).

22. 22 Ghadami, F., Aghdam, A. S. R. \& Ghadami, S. Characterization of MCrAlY/nano-Al2O3 nanocomposite powder produced by high-energy mechanical milling as feedstock for high-velocity oxygen fuel spraying deposition. International Journal of Minerals, Metallurgy and Materials 28, 1534-1543, doi:10.1007/s12613-020-2113-1 (2021).

23. 23 Ghadami, F., Sabour Rouh Aghdam, A. \& Ghadami, S. Isothermal and Cyclic Oxidation Behavior of HVOF-Sprayed NiCoCrAlY Coatings: Comparative Investigations on the Conventional and Nanostructured Coatings. Journal of Thermal Spray Technology 29, 1926-1942, doi:10.1007/s11666-020-01111-9 (2020).

24. 24 Saeedi, B., Sabour Rouh Aghdam, A. \& Gholami, G. A study on nanostructured in-situ oxide dispersed NiAl coating and its high temperature oxidation behavior. Surf. Coat. Technol. 276, 704-713, doi:https://doi.org/10.1016/j.surfcoat.2015.05.042 (2015).

25. 25 Daroonparvar, M., Hussain, M. S. \& Yajid, M. A. M. The role of formation of continues thermally grown oxide layer on the nanostructured NiCrAlY bond coat during thermal exposure in air. Appl. Surf. Sci. 261, 287-297, doi:https://doi.org/10.1016/j.apsusc.2012.08.002 (2012).

26. 26 Ghadami, F., Sabour Rouh Aghdam, A., Zakeri, A., Saeedi, B. \& Tahvili, P. Synergistic effect of CeO2 and Al2O3 nanoparticle dispersion on the oxidation behavior of MCrAlY coatings deposited by HVOF. Ceram. Int. 46, 4556-4567, doi:https://doi.org/10.1016/j.ceramint.2019.10.184 (2020).

27. 27 Ghadami, F., Sabour Rouh Aghdam, A., Ghadami, S. \& Zeng, Q. Effect of vacuum heat treatment on the oxidation kinetics of freestanding nanostructured NiCoCrAlY coatings deposited by high-velocity oxy-fuel spraying. J. Vac. Sci. Technol., A 38, 022601, doi:10.1116/1.5132416 (2020).

28. 28 Cheng, K.-C., Chen, J.-H., Stadler, S. \& Chen, S.-H. Properties of atomized AlCoCrFeNi high-entropy alloy powders and their phase-adjustable coatings prepared via plasma spray process. Applied Surface Science 478, 478-486, doi:https://doi.org/10.1016/j.apsusc.2019.01.203 (2019). 
29. 29 Odhiambo, J. G., Li, W., Zhao, Y. \& Li, C. Porosity and Its Significance in Plasma-Sprayed Coatings. Coatings 9, doi:10.3390/coatings9070460 (2019).

30. 30 Yue, T. M., Xie, H., Lin, X., Yang, H. \& Meng, G. Microstructure of Laser Re-Melted AlCoCrCuFeNi High Entropy Alloy Coatings Produced by Plasma Spraying. Entropy 15, doi:10.3390/e15072833 (2013). 